\title{
Editorial
}

\section{Structural Damage Modelling and Assessment}

\author{
Anaxagoras Elenas, ${ }^{1}$ Yuri Petryna, ${ }^{2}$ and Nawawi Chouw $^{3}$ \\ ${ }^{1}$ Department of Civil Engineering, Democritus University of Thrace, 67100 Xanthi, Greece \\ ${ }^{2}$ Department of Civil Engineering, Technical University Berlin, 13355 Berlin, Germany \\ ${ }^{3}$ Department of Civil and Environmental Engineering, The University of Auckland, New Zealand
}

Correspondence should be addressed to Anaxagoras Elenas; elenas@civil.duth.gr

Received 17 March 2014; Accepted 17 March 2014; Published 3 April 2014

Copyright (C) 2014 Anaxagoras Elenas et al. This is an open access article distributed under the Creative Commons Attribution License, which permits unrestricted use, distribution, and reproduction in any medium, provided the original work is properly cited.

A lot of research work has been done during the last decades, focusing on the structural damage modelling and assessment. This rapidly growing scientific field forms a basis for efficient structural design, health monitoring, and lifetime management. The computer-based modelling and assessment make a quantification of the structural damage evolution possible. It is an important tool for prediction or explanation of damage in a large variety of civil engineering structures. In this context, the structures can be real, planned, or experimental specimens. Several new damage simulation and evaluation approaches, including analytical, numerical, and intelligent procedures, have been considered in the present special issue.

A. Elenas presents two statistical methods for the approximate evaluation of the postseismic damage status of buildings based on twenty intensity parameters of seismic excitations. The first is multilinear regression analysis, and the second is discriminant analysis. The overall damage index of Park and Ang, the maximum interstory drift ratio, and the maximum softening of DiPasquale and Cakmak are used to describe the structural damage status.

W. B. Krätzig and Y. S. Petryna apply recent research on structural damage description to earthquake-resistant design concepts. They define damage indicators, which are able to quantify the arising structural damage. Such damage measures are based on dissipated energies of virtual mode shapes/modal forces which can be derived from the tangential stiffness matrix in the framework of nonlinear finite element analysis. The paper bridges a gap to the quasistatic seismic safety concepts of most design codes. The developed concept is checked by reanalyses of two experimentally investigated reinforced concrete frames.
J. Hou et al. present a parameter estimation method for structural health monitoring based on the combined measured global frequencies and local frequencies of the structure. Initially, an experiment provides low-order modes which can reflect the global information of the structure. Then, a mass is added to the structural member to increase the local dynamic characteristic and to make the member have the local primary frequency, which belongs to structural local frequency and is sensitive to local parameters. Finally, the parameters of the structure can be optimized accurately using the combined structural global frequencies and structural local frequencies.

M. Saadi and A. Athanasopoulos-Zekkos present a GIS enabled approach for assessing damage potential of levees systems. Spatial variability of soil properties is correlated with regional variables such as distance from the nearest river segment, river meandering sinuosity index, and surface geology. A geostatistical ordinary Kriging approach is used for developing these correlations. Soil strength parameters of identified levee stratigraphy layers were statistically analyzed using a geostatistical ordinary Kriging approach and correlated with preselected regional variables. Excessive underseepage and loss of freeboard due to soil liquefaction are evaluated as the two damage indices for earthen levees.

N. Nanos and D. Begg investigate the influence of alternative infill wall topologies in terms of a frame structure's seismic behavior and damage distribution characteristics. Their work was carried out with utilizing nonlinear dynamic analyses combined with a set of spectrum compatible artificial accelerograms for all individual cases to obtain the relevant structural response. Structural damage results were 
quantified by the global structure damage index of Park and Ang and the maximum interstory drift ratio.

Q. Zhang et al. present an effective procedure for a simultaneous identification of moving vehicles and structural damage based on a virtual distortion method. The vehicle parameters and the structural damage are treated as optimization variables. Using a moving dynamic influence matrix the response of the damaged system to given optimization variables could be computed quickly without the need of a numerical simulation and the repeated assembly of the timevariant system parameter matrix at each time step.

A. J. Lobbestael et al. investigate the effects of progressive failure on flood embankments with underlying thin layers of soft and sensitive soils. A parametric analysis is conducted to investigate the effect of thin layers of soft sensitive soils on the stability of flood embankments. A flood embankment is modeled by the limit equilibrium method and the finite element method. The foundation profile is altered to determine the extent to which varying soft and sensitive soils affect the stability of the embankment, with respect to progressive failure.

S. Alexandrov and Y. Mustafa present an exact analytic solution for a class of elastic-plastic models with damage evolution. Special attention is devoted to the qualitative behavior of the solution in the vicinity of the bimaterial interface.

H. He et al. present a global damage index based on multiple linear force-deformation curves in pushover analysis to evaluate the damage of reinforced concrete structures. Multiple damage indices about displacement and energy for performance-based design are considered. The relation of multiple damage indices and the fuzzy damage set is presented by a comprehensive fuzzy evaluation. Thus, a method is proposed for performance-based multiple fuzzy seismic damage assessment of reinforced concrete frame structures.

Q. W. Yang proposes an exact flexibility perturbation technique for damage identification in statically determinate structures, which is based on matrix spectral decomposition and minimum-rank update theory. The procedure considered can reveal a reliable extent of damage by a simple computation without any higher-order approximation or iteration, regardless of whether the damage is small or large.

O. Panagouli and K. Iordanidou examine the postcracking strength of a reinforced concrete shear wall by taking into account the complex geometry of the crack and the mixed friction-plastification mechanisms that develop in the vicinity of the crack. Because of the significance of the crack geometry, a multiresolution analysis based on fractal geometry is performed, taking into account the size of the aggregates of concrete. The constitutive materials are assumed to have elastic-plastic behavior.

Y. Jiao et al. present an effective strategy for eliminating temperature effects in damage identification of bridges. Thereby the authors use adaptive neurofuzzy inference system (ANFIS) that combines the advantages of neural networks and fuzzy inference system used as damage identification algorithm.
By compiling these papers, the editors hope that the readers will benefit from the latest development in the field of structural damage modelling and assessment of civil engineering structures.

Anaxagoras Elenas Yuri Petryna

Nawawi Chouw 


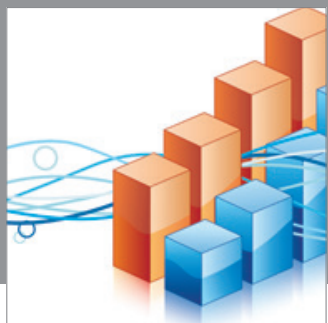

Advances in

Operations Research

mansans

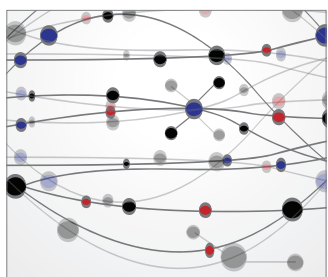

The Scientific World Journal
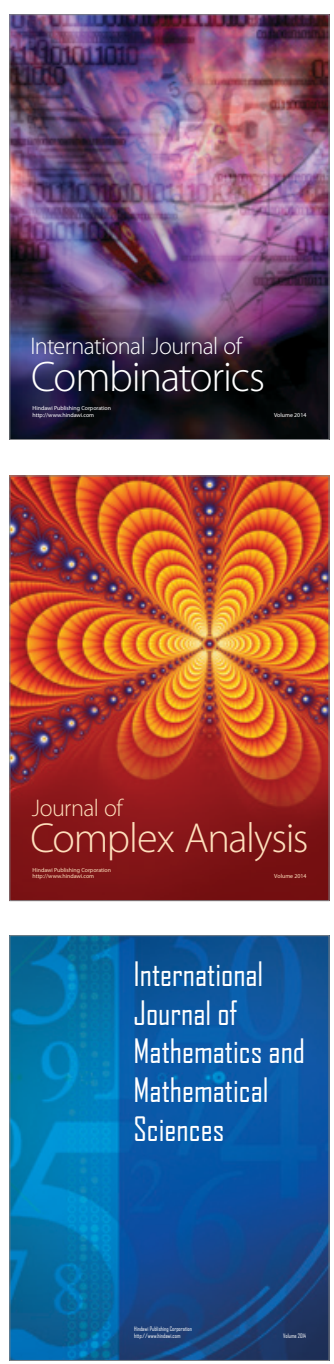
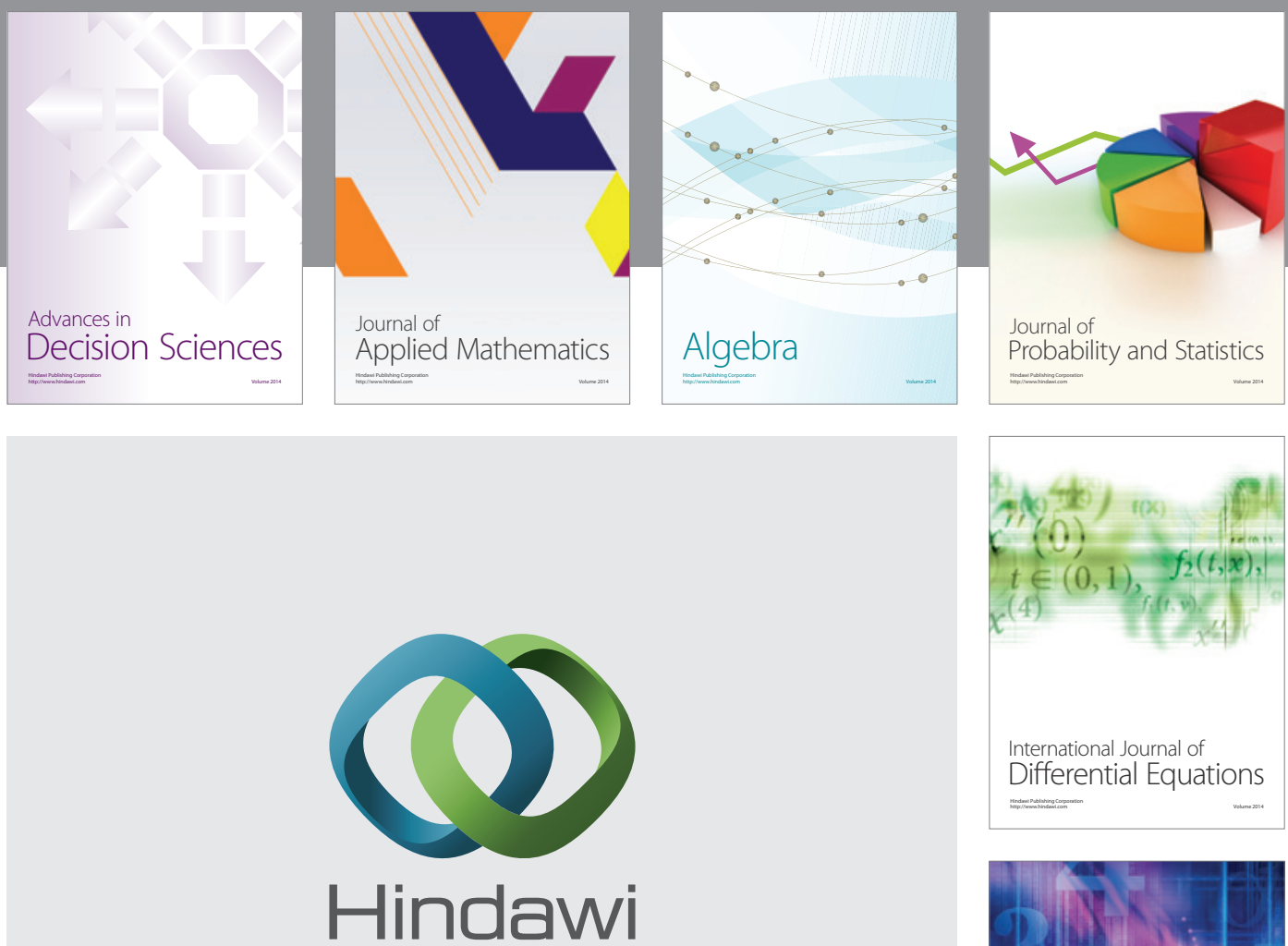

Submit your manuscripts at http://www.hindawi.com
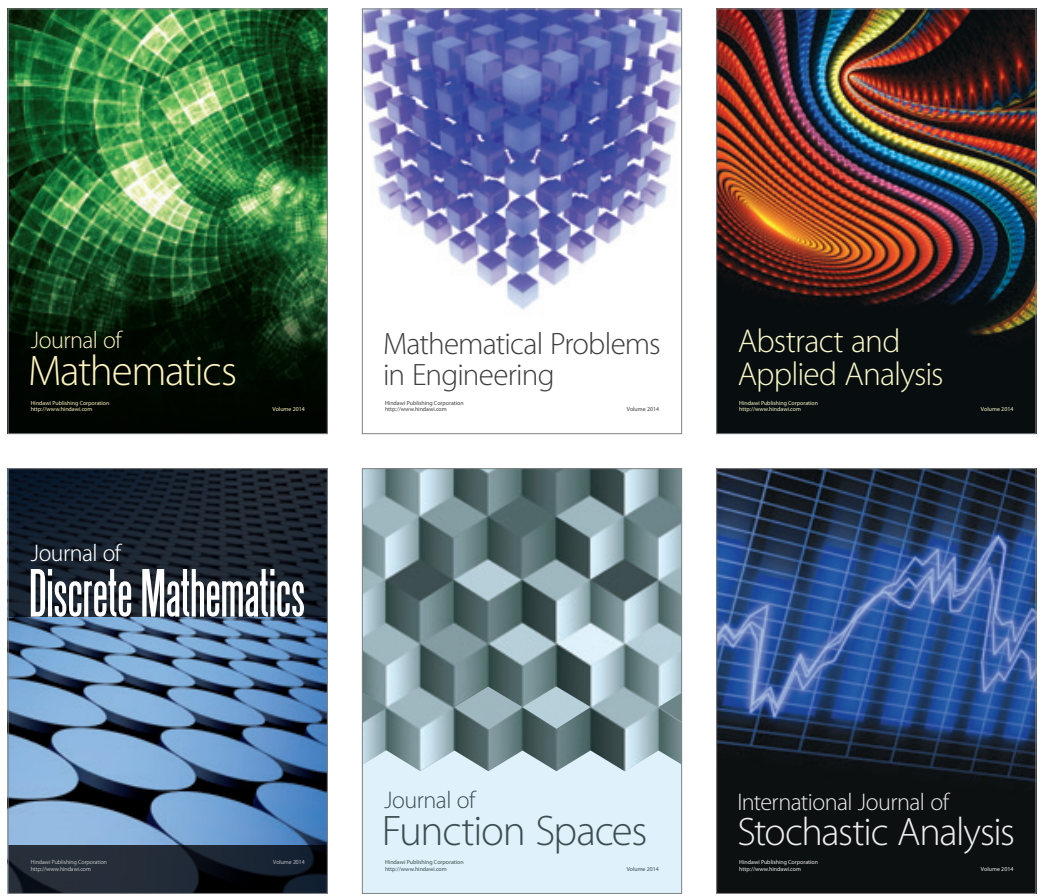

Journal of

Function Spaces

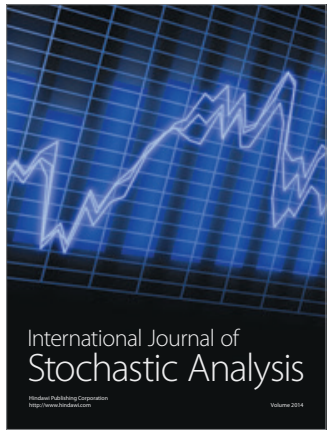

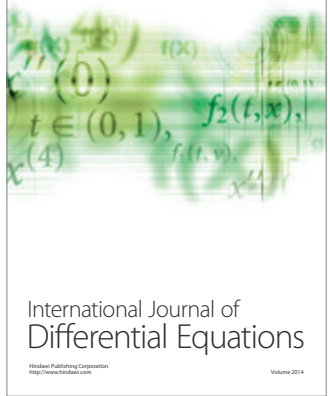
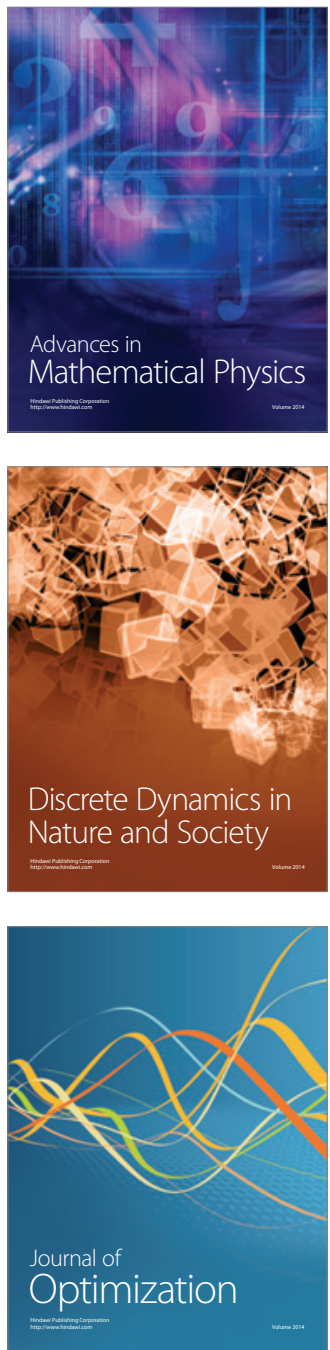